An analysis of fire-retardant materials for wooden building structures is carried out and the need to develop reliable methods for studying the process of ignition and flame propagation on the surface of a building structure, necessary for creating new types of fire-retardant materials, is found. Therefore, it is necessary to determine the conditions for forming a thermal conductivity barrier and find a mechanism for inhibiting heat transfer to the material. In this regard, a computational and analytical method for determining thermal conductivity when using a fire-retardant varnish as a coating is developed, which allows assessing the coefficient of thermal conductivity under high temperature action. According to experimental data and theoretical dependences, the coefficient of thermal conductivity of the fire-retardant coked foam layer of $0.36 \mathrm{~W} /(\mathrm{m} \cdot \mathrm{K})$ is calculated, which, accordingly, ensures the heat resistance of wood.

As a result of research, it is proved that the process of heat insulation of a wooden structure consists in the formation of sootlike products on the surface of natural combustible material. This made it possible to determine the conditions for fireproofing wood by forming a thermal conductivity barrier during the decomposition of varnish into foamed coke. Experimental studies confirmed that a sample of fireproof wood withstood the temperature effect of the heat flux for $900 s$. The maximum possible temperature penetration through the coating is evaluated. It is found that under the temperature effect on the sample, which significantly exceeds the ignition temperature of wood, on the unheated surface of the sample, this value did not exceed $180^{\circ} \mathrm{C}$. Thus, there is reason to assert the possibility of directional regulation of wood fire protection processes using fire-retardant coatings that can form a protective layer on the material surface that inhibits wood burnout

Keywords: protective agents, weight loss, surface treatment, wood burnout

\section{DETERMINATION OF REGULARITIES OF HEAT RESISTANCE UNDER FLAME ACTION ON WOOD WALL WITH FIRE-RETARDANT VARNISH}

Y u. Ts a pko

Doctor of Technical Sciences**

V. D. Glukhovsky Scientific Research Institute

of Binders and Materials

Kyiv National University of Construction and Architecture Povitroflotsky ave., 31, Kyiv, Ukraine, 03037

E-mail: juriyts@ukr.net

V. Lo m a h a

Posgraduate Student*

E-mail: lomaga39@gmail.com

A. T s a p k o

Posgraduate Student*

E-mail: alekseytsapko@gmail.com

S. Mazu r c h u k

$\mathrm{PhD*}$

E-mail: mazurchuk.s.m@ukr.net

O. Horbachova

$\mathrm{PhD*}$

E-mail: gorbachova.sasha@ukr.net

D. Zavialov

Junior Researcher

Department of Research on Quality and Storage Conditions of Petroleum Products and an Industrial Group of Goods

Ukrainian State Research Institute «Resurs»

Kazymira Malevycha str., 84, Kyiv, Ukraine, 03150

E-mail: lazarovuch@ukr.net

*Department of Technology and Design of Wood Products** **National University of Life and Environmental Sciences of Ukraine

Heroiv Oborony str., 15, Kyiv, Ukraine, 03041
Received date 13.07.2020 Accepted date 11.08.2020 Published date 25.08.2020
Copyright (C 2020, Yu. Tsapko, V. Lomaha, A. Tsapko, S. Mazurchuk, O. Horbachova, D. Zavialoz This is an open access article under the CC BY license (http://creativecommons.org/licenses/by/4.0)

\section{Introduction}

Wood, as a building material, is widely used in construction and architecture due to its mechanical and operational properties. But due to high flammability, it is a fire-hazardous material.

Fires that have occurred in recent years have shown an increase in fire hazards, in particular, high temperatures and their impact on wood. In addition, the range of participation of various synthetic materials, hydrocarbons capable of high heat generation during combustion in fires has recently expanded.

Fireproofing with modern effective means can significantly affect or eliminate the risk of fire, by preventing the free access of oxygen, which contributes to the destruction of wood and acceleration of the combustion process [1,2]. In addition, the coating allows slowing down the heating of the material due to the formation of a protective layer and retaining its functions in case of fire for a specified period of time [3]. 
Modern fireproofing compositions can create heat shields on the surface of structural elements that can withstand high temperatures and direct fire and slow down the heating of the material. That is, they are able to retain their functions in case of fire for a specified period of time, thereby making wood low-combustible.

However, the coating changes the color of the wood surface, which is reflected accordingly on the aesthetic characteristics of the wood. Given the significant requirements for these indicators, the question arises as to the use of transparent fireproofing compositions and determining their effectiveness

Therefore, the study of the heat resistance of wood and effect of the coating on this process when applying varnish is part of ensuring fire resistance and, accordingly, determines the need for such research.

\section{Literature review and problem statement}

In [4], the effect of fireproofing coating covering swelling and heat transfer is shown. But there are still unresolved issues related to the mechanism of coked foam formation. The reason for this may be the subtleties of creating a protective layer, which accordingly makes such studies difficult. In addition, [5] considers the effect of a vegetable binder on the formation of heat-insulating materials, but the issue of fire resistance remains unresolved. In [6], the fire-retardant ability is investigated according to such combustion characteristics as weight loss, burning rate, maximum burning rate, but chemical changes caused by these factors are not indicated. However, there are still questions about the impact of decomposition of coating components on the fire-retardant ability. The materials presented in [7] are characterized by high fire resistance, but temperature transitions during thermal action are not shown.

The effectiveness of organic compositions is described in [8], where due to the action of flame retardants based on polyphosphoric acids and foaming agents it is possible to significantly influence the formation of a protective coked foam layer. However, there is a need to study changes in thermal conductivity and determine the effect of the coating with the formation of a coked foam layer.

In [9], the most promising fireproofing compositions of swelling coatings are presented, which are complex systems of organic and inorganic components. But the issues concerning the manifestation of the joint action of the coating components during foaming remain unresolved. In addition, changes in the coating surface are not taken into account.

A significant increase in the resistance, density and strength of the protective layer is achieved due to the targeted formation of certain additives that form high-temperature compounds [10]. However, most compositions change the color of the surface and do not provide the original appearance of the material.

The paper [11] describes epoxy resin composites, reinforced and inhibited from fire with surface-treated carbon fibers. However, such coatings have a dark color and when treated change the surface of the wooden product.

In addition, many coatings have a number of disadvantages, such as the application of individual components, loss of functional properties with increasing temperature [12]. This means that it is not determined how the decomposition of the flame-retardant coating proceeds.
Studies of protective materials made using liquid glass are also conducted [13]. The results are aimed at developing technologies and materials that combine fire resistance, low thermal conductivity and processability of products and protective coatings. However, the viability of the coating, the mechanism of heat insulation are not determined.

Thus, from the literature, it is found that fire-retardant coatings change the color of the wood surface and the parameters that ensure the fire resistance of wood, as well as what affects this process are not determined. Therefore, determining the parameters of wood fireproofing means and the impact of their components necessitated research in this direction.

\section{The aim and objectives of the study}

The aim of the work is to identify the patterns of heat resistance of wood when applying a fire-retardant varnish coating. This makes it possible to justify the fireproofing of wood with transparent coatings.

To achieve the aim, the following objectives were set:

- to model the process of heat propagation through the thickness of fireproofed wood;

- to determine features of reduction of the heat permeability of wood during thermal action on the sample when using a fire-retardant varnish.

\section{Materials and methods for studying the burnout rate of wood}

\section{1. Research materials used in the experiment}

To determine the flammability of wood, samples of straightgrained pine wood with a size of $310 \times 140 \times 6 \mathrm{~mm}$ and a density of $420 \div 470 \mathrm{~kg} / \mathrm{m}^{3}$ were used. The wood surface was coated with a fireproofing agent for wooden structures ( $\ll$ FIREWALLLACQUER») (Ukraine) with a flow rate of $570 \mathrm{~g} / \mathrm{m}^{2}$ and protective finishing varnish «Alkyd-Polyurethane varnish» (TM «Composite») (Ukraine) with a flow rate of $57 \mathrm{~g} / \mathrm{m}^{2}$ (Fig. 1).

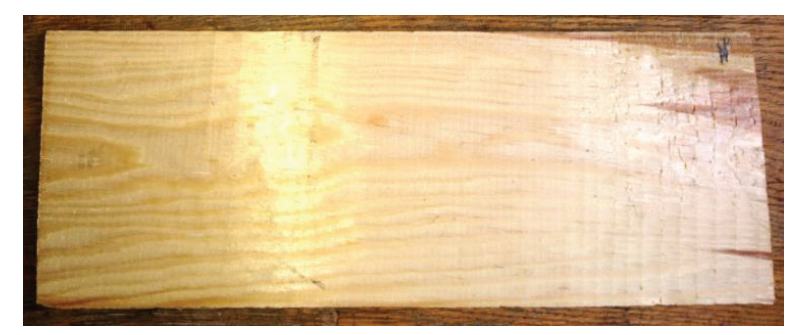

Fig. 1. Model wood samples for testing

After drying to a constant weight, the treated wood samples were tested.

4. 2. Methods for determining the burnout rate of wood

For the study, an installation for determining the flammability index of materials, which was additionally equipped with a device for sample surface temperature measurement during tests with a thermocouple we used (Fig. 2).

A method for determining the parameters of ignition and flame propagation in wood includes the exposure of the sample to the electric radiation panel and ignition of the sample by the burner, measuring the maximum temperature on the opposite surface and the time of its achievement. 


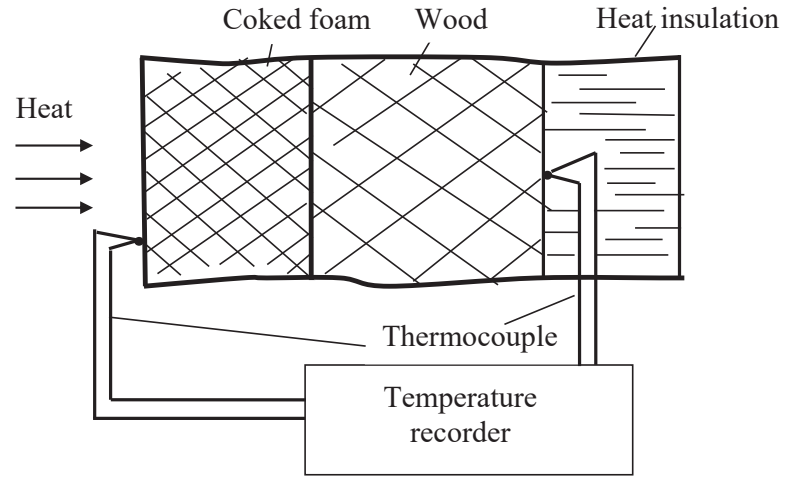

Fig. 2. Scheme of sample heat resistance testing

\section{Modeling of wood wall heat conduction during fire-retardant coating swelling}

As a result of wood treatment with fire-retardant coatings, under the action of heat flow, the direction of decomposition of the protective material changes towards the formation of non-combustible gases and hardly flammable coke residue. It is largely able to absorb heat and reduce heat transfer to the material.

In view of the above, the question arises as to the study of the thermophysical properties of the fire-retardant coked foam layer during heat exposure.

It should be noted that the determination of the thermophysical characteristics of the fire-retardant coked foam layer is associated with a number of obstacles, namely the need to measure the temperature in the coked foam layer, which changes over time.

In order to determine the thermophysical characteristics of the wall of fireproof wood, a method for solving the problem of thermal conductivity for a two-layer plate with different thermophysical properties is proposed. At the initial time, a time-constant heat flux $q_{0}$ is applied to the left face of the surface of the fireproof wood sample. That is, the sample is instantly heated to a temperature that is kept constant throughout the heating process. In addition, the temperature is distributed through the coating until the critical wall temperature is reached. The right face of the sample is adiabatized $(q=0)$.

Three areas were considered (Fig. 3 ):

-1 - external environment, $x<0$;

-2 - area of the swollen coked foam layer, $0<x \leq h(h-$ the coordinate of coating film transformation into a swollen coked foam layer, $\mathrm{m})$;

-3 - wood (sample material with solid coating) $(H-h), \mathrm{m}$.

Differential equations of heat transfer on the surface of the two-layer plate are as follows:

- for the coating:

$$
\frac{\partial^{2} T_{2}(x, \tau)}{\partial x^{2}}-\frac{1}{\phi_{2}^{2}} \frac{\partial T_{2}(x, \tau)}{\partial \tau}=0,(\mathrm{t}>0 ; 0<x<h)
$$

- for wood:

$$
\frac{\partial^{2} T_{3}(x, \tau)}{\partial x^{2}}-\frac{1}{\phi_{3}^{2}} \frac{\partial T_{3}(x, \tau)}{\partial \tau}=0,(\mathrm{t}>0 ; h<x<H)
$$

with initial and boundary conditions:

$$
\begin{aligned}
& T_{2}(x, 0)=T_{3}(x, 0)=T_{0}, \\
& \lambda_{2} \frac{\partial T_{2}(x, \tau)}{\partial x}=q_{0}=\text { const, } \\
& T_{2}(R, \tau)=T_{3}(R, \tau), \\
& \lambda_{2} \frac{\partial T_{2}(R, \tau)}{\partial x}=\lambda_{3} \frac{\partial T_{3}(R, \tau)}{\partial x}, \\
& \lambda_{3} \frac{\partial T_{3}(x, \tau)}{\partial x}=0,
\end{aligned}
$$

where $T_{2}(x, \tau), T_{3}(x, \tau)$ is the temperature field of the swollen coked foam layer of the coating and wood at points with coordinates $x$ at time $\tau ; \tau ; \phi=\sqrt{a} ; a=\lambda / c \cdot \rho ; a_{2}, a_{3}$ are the coefficients of thermal diffusivity of the coating and wood; $\lambda_{2}, \lambda_{3}$ are the coefficients of thermal conductivity of the coating and wood; $h, H-h$ is the thickness of the coating and wood.

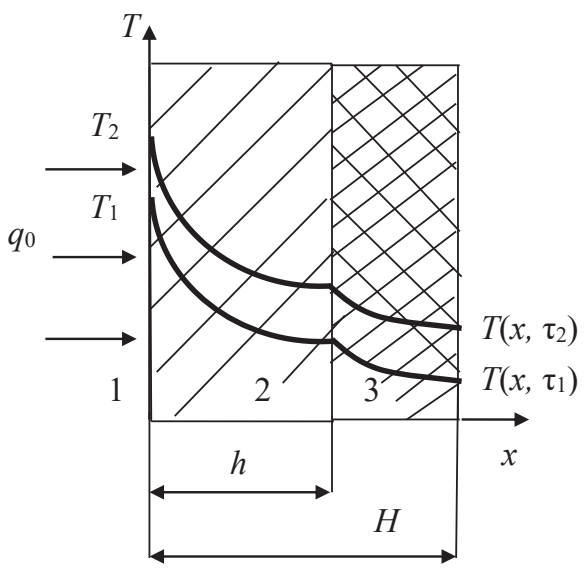

Fig. 3. Scheme of swelling of the fire-retardant coating on the fabric: 1 - external environment; 2 - coked foam layer; 3 - source material (fireproof fabric)

After mathematical transformations, the exact analytical solution of the direct boundary value heat conduction problem (1)-(7) can be obtained provided that the temperature field $T_{3}(x, \tau)$ for wood at each time point $\tau$ can be found. The temperature field $T_{2}(x, \tau)$ of the investigated coating can be given as follows [14]:

$$
T_{2}(x, \tau)-T_{2}(0, \tau)=-\frac{q_{0}}{\lambda_{2}} \cdot x+\frac{\beta(\tau)}{2 \phi_{2}} \cdot x^{2} .
$$

According to [15], the rate of wood temperature change over time depends on the heat flux $q_{0}$, geometric dimensions $h,(H-h)$ and volumetric heat capacities of the coating $c_{2} \rho_{2}$ and wood $c_{3} \rho_{3}$ :

$$
\beta(\tau)=\frac{\partial T_{3}(h, \tau)}{\partial \tau}=\frac{q_{0}}{\left[c_{2} \rho_{2} \cdot h+c_{3} \rho_{3} \cdot(H-h)\right]},
$$

where $\beta(\tau)$ is the rate of wood temperature change over time.

In addition, the rate of wood temperature change can be represented by experimental data:

$$
\beta(\tau)=\frac{\partial T_{3}(x, \tau)}{\partial \tau}=\frac{T_{3}\left(h, \tau_{2}\right)-T_{3}\left(h, \tau_{1}\right)}{\tau_{2}-\tau_{1}},
$$


Equating (9) and (10), we obtain a calculation to determine the volumetric heat capacity of the coked foam of the coating:

$$
c_{2} \rho_{2}=\frac{1}{h}\left[\frac{q_{0}\left(\tau_{2}-\tau_{1}\right)}{T_{3}\left(h, \tau_{2}\right)-T_{3}\left(h, \tau_{1}\right)}-c_{3} \rho_{3}(H-h)\right] .
$$

Determination of thermophysical characteristics of untreated wood was carried out according to the method described in [16].

If we introduce $x=0$ and $x=h$ in the relation (8), we obtain the equation:

$$
\begin{aligned}
& T_{2}(0, \tau)=T_{2}(0, \tau), \\
& T_{2}(h, \tau)=T_{2}(0, \tau)-\frac{q_{0}}{\lambda_{2}} \cdot h+\frac{\beta(\tau)}{2 \phi_{2}} \cdot h^{2} .
\end{aligned}
$$

Taking into account [15] on the basis of $\phi=\sqrt{a}$ from (10) it is possible to obtain a formula for calculating the thermal diffusivity of wood:

$$
a=\frac{(H-h)^{2}}{2\left(\tau_{2}-\tau_{1}\right)} .
$$

According to the measured experimental value, the temperature difference $\Delta T$ of the investigated coked foam layer will be:

$$
T_{2}(h, \tau)-T_{2}(0, \tau)=\frac{q_{0} \cdot h}{\lambda_{2}}-\frac{\beta(\tau) \cdot h^{2}}{2 \lambda_{2}} \cdot c_{2} \rho_{2} .
$$

Hence the relation of thermal conductivity:

$$
\lambda_{2}=\frac{q_{0} \cdot h-0,5 \beta(\tau) \cdot h^{2} \cdot c_{2} \rho_{2}}{T_{2}(h, \tau)-T_{2}(0, \tau)} .
$$

According to the obtained dependence (16), we calculate the thermal conductivity of the coked foam of the coating by the temperature difference and the rate of its change (10), geometric dimensions and volumetric heat capacity of the coked foam (11).

Thus, the dependences are obtained that provide the values of the thermal conductivity of the coked foam of fireproof wood during swelling of the fire-retardant coating. At the same time, they provide an opportunity to directly calculate changes in thermal conductivity depending on temperature effect.

\section{Results of determining the wood sample surface temperature under thermal exposure}

To determine the thermophysical characteristics of wood, studies were conducted on its thermal conductivity under the action of a heating device (Fig. 4).
The results of studies to determine the maximum temperature and duration of the induction time of temperature transfer through the wood layer were performed in accordance with [16], the results are shown in Fig. 5.

As can be seen from Fig. 5, under the action of the heater on the pine wood samples, intense heat transfer and slight increase in temperature on the back surface of the sample for about 900 s began.

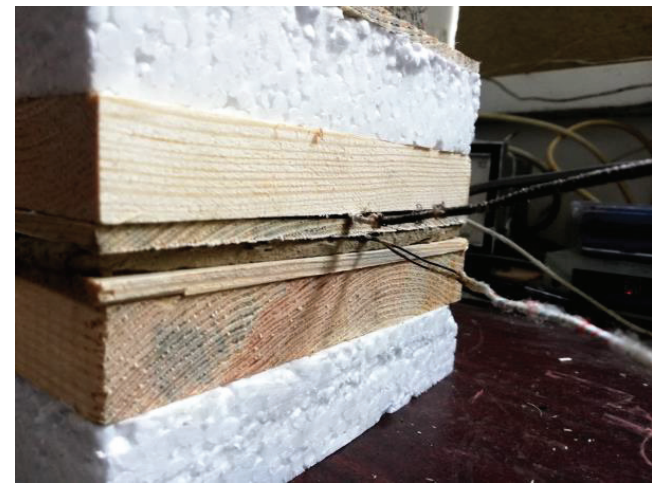

Fig. 4. Process of determining the thermal conductivity of the wood sample under the action of the heater

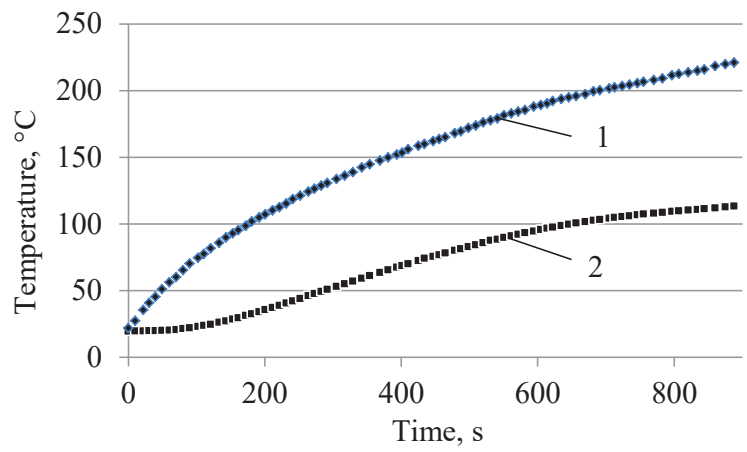

Fig. 5. Results of testing the thermal conductivity of pine wood: 1 - heating curve, 2 - temperature on the back surface of untreated wood

Based on the results of the measured temperature, the thermophysical characteristics of dry pine wood products were calculated (Table 1).

Studies show that such a temperature effect of the wood sample demonstrated thermophysical properties close to ordinary pine wood.

Fig. 6 shows the process of ignition and flame propagation on the varnished wood sample.

As can be seen from Fig. 6, under the action of temperature, the protective varnish swelled and formed a protective layer of coke on the sample surface. This significantly

\begin{tabular}{|c|c|c|c|c|c|c|c|}
\hline \multirow[b]{2}{*}{ Material } & \multirow{2}{*}{$\begin{array}{l}\text { Thick- } \\
\text { ness, mm }\end{array}$} & \multirow{2}{*}{$\begin{array}{l}\text { Weight, } \\
\text { g }\end{array}$} & \multicolumn{5}{|c|}{ Estimated characteristics of wood products } \\
\hline & & & $\begin{array}{l}\text { Density } \\
\rho, \mathrm{kg} / \mathrm{m}^{3}\end{array}$ & $\begin{array}{l}\text { Thermal activity, } \\
\mathrm{W} \cdot \mathrm{s}^{1 / 2} /\left(\mathrm{m}^{2} \cdot \mathrm{K}\right)\end{array}$ & $\begin{array}{l}\text { Thermal diffu- } \\
\text { sivity, } \mathrm{m}^{2} / \mathrm{s}\end{array}$ & $\begin{array}{l}\text { Thermal conduc- } \\
\text { tivity } \lambda, W /(\mathrm{m} \cdot \mathrm{K})\end{array}$ & $\begin{array}{c}\text { Heat capacity, } \\
\mathrm{J} /(\mathrm{kg} \cdot \mathrm{K})\end{array}$ \\
\hline Wood $120 \times 300 \mathrm{~mm}$ & 6 & 89.6 & 414.8 & 340.3 & $18 \cdot 10^{-6}$ & 0.308 & 2.38 \\
\hline
\end{tabular}
affected the process of wood burning and heat transfer in thickness, but in the area of the greatest thermal effect, the wood changed color.

Table 1

Thermophysical characteristics of dry pine wood products 


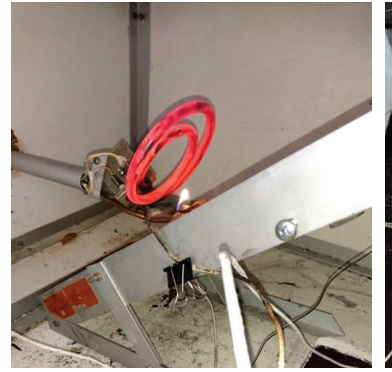

a

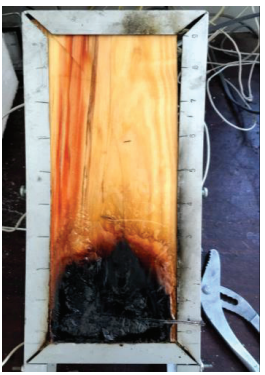

$b$

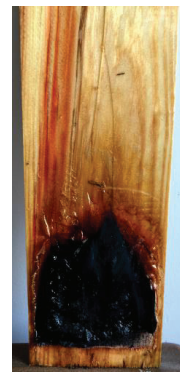

c
Fig. 6. Sample burning process:

$a$ - flame effect; $b$ - swelling of fire-retardant varnish; $c-$ wood after tests

Fig. 7 shows the temperature dependence on the sample surface and at points according to Fig. 2. As can be seen from Fig. 7, under the action of the radiation panel, a heat flux with a capacity of $32 \mathrm{~kW} / \mathrm{m}^{2}$ was created on the surface of the sample. It created a temperature that significantly exceeded the ignition temperature of the wood, and on the unheated surface did not exceed $180^{\circ} \mathrm{C}$. Under this action, a layer of coked foam with a size of $6 \div 7 \mathrm{~mm}$ was formed on the surface of the sample, which insulated the wood from high temperature.

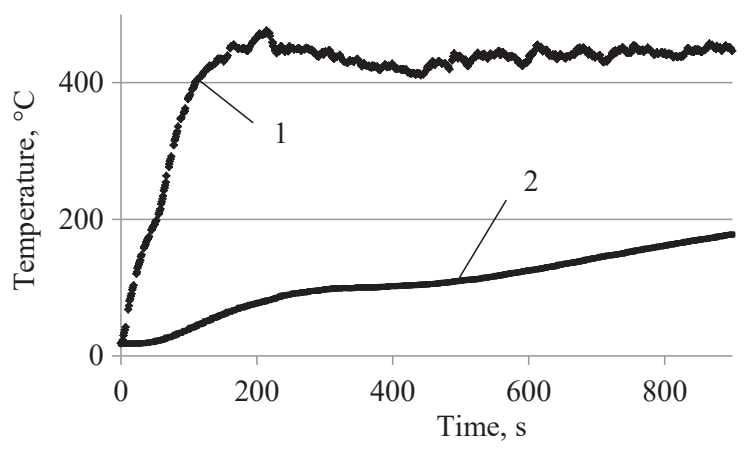

Fig. 7. Temperature dependence during fire resistance testing of the wooden structure coated with fireproof fabric on the duration of fire exposure: 1 - on the surface of fireproof fabric; $2-$ behind the fireproof fabric and on the wood surface; 3 - on the unheated wood surface

According to the temperature measurements obtained during the tests (Fig. 7), the thermophysical properties of coked foam were calculated using the obtained dependences (11) and (16). Thus, the volumetric heat capacity of the coked foam layer was $17.114 \mathrm{~kJ} /\left(\mathrm{m}^{3} \cdot \mathrm{K}\right)$, and the thermal conductivity coefficient was $0.36 \mathrm{~W} /(\mathrm{m} \cdot \mathrm{K})$, respectively.

\section{Discussion of the results of the study of the heat transfer process}

When using fire-retardant varnishes to protect wood under the thermal action of high-temperature flames, as indicated by research results (Fig. 6,7), there is a natural process of coating swelling under the influence of temperature and formation of a protective coked foam layer, which slows down heat conduction processes. Obviously, such a mechanism of the coating effect is a factor in regulating the degree of coke formation and effectiveness of thermal insulation. This agrees with the data known from [4, 6], the authors of which also associate the effectiveness of thermal protection against swelling with adding flame retardants. This paper fully presents the mechanism of fire protection of organic natural materials, movement and insulation of high temperature, but there is a need to evaluate this process, create a physical and mathematical model. Unlike the results of studies [7,8], the data on the effect of swelling on heat transfer to the material and changes in thermal insulation properties suggest the following:

- the main regulator of the process is not only the decomposition of flame retardants under the action of temperature with heat absorption and release of incombustible gases, but also the formation of a coked foam layer and inhibition of the oxidation process in the gas and condensed phase;

- a significant impact on the process of protection of combustible material when applying a fire-retardant coating is made in the direction of reactions in the pre-flame region towards the formation of soot-like products on the surface of natural combustible material.

Such conclusions can be considered practical, because they allow a reasonable approach to determining the necessary formulation of a flame retardant. From a theoretical point of view, they argue about the determination of the fire protection mechanism, which is a certain advantage of this study. The results of determining the thermal conductivity of protected wood (Fig. 7) indicate an ambiguous effect of the nature of protection means on temperature. In particular, this implies the availability of data sufficient for efficient temperature reduction and detection of the time of heat resistance fall. This detection will allow investigating the transformation of the coating surface into coked foam, which moves towards an elevated temperature, and determining those variables that significantly affect the transformation mechanism of this process.

\section{Conclusions}

1. Modeling of the process of heat transfer in wood during its protection by the coating is carried out, the coefficient of thermal conductivity is determined and dependences that allow determining the change of heat transfer dynamics during the coating swelling are obtained. According to the experimental data and dependences obtained, the thermal conductivity of wood is calculated, due to the formation of a heat-insulating coked foam layer, and is $0.36 \mathrm{~W} /(\mathrm{m} \cdot \mathrm{K})$, respectively.

2. Features of inhibiting the heat transfer to the material treated with a fire-retardant varnish consist in the formation of a heat-protective coke layer on the wood surface. Thus, a temperature was created on the surface of the sample that significantly exceeded the ignition temperature of the wood, and on the unheated surface did not exceed $180^{\circ} \mathrm{C}$.

\section{Acknowledgments}

The authors express their gratitude for the financial support of the work performed under the funding budget No. 3 DB-2018, as well as for the development of scientific topics in the COST Action FP 1407 scientific cooperation program «Understanding wood modification using an integrated scientific and environmental approach» under the European Union program HORIZON 2020. 


\section{References}

1. Tsapko, Y., Kyrycyok, V., Tsapko, A., Bondarenko, O., Guzii, S. (2018). Increase of fire resistance of coating wood with adding mineral fillers. MATEC Web of Conferences, 230, 02034. doi: https://doi.org/10.1051/matecconf/201823002034

2. Tsapko, Y., Bondarenko, O. P., Tsapko, A. (2019). Research of the Efficiency of the Fire Fighting Roof Composition for Cane. Materials Science Forum, 968, 61-67. doi: https://doi.org/10.4028/www.scientific.net/msf.968.61

3. Tsapko, Y. V., Yu Tsapko, A., Bondarenko, O. P., Sukhanevych, M. V., Kobryn, M. V. (2019). Research of the process of spread of fire on beams of wood of fire-protected intumescent coatings. IOP Conference Series: Materials Science and Engineering, 708, 012112. doi: https://doi.org/10.1088/1757-899x/708/1/012112

4. Krüger, S., Gluth, G. J. G., Watolla, M.-B., Morys, M., Häßler, D., Schartel, B. (2016). Neue Wege: Reaktive Brandschutzbeschichtungen für Extrembedingungen. Bautechnik, 93 (8), 531-542. doi: https://doi.org/10.1002/bate.201600032

5. Xiao, N., Zheng, X., Song, S., Pu, J. (2014). Effects of Complex Flame Retardant on the Thermal Decomposition of Natural Fiber. BioResources, 9 (3). doi: https://doi.org/10.15376/biores.9.3.4924-4933

6. Gaff, M., Kačík, F., Gašparík, M., Todaro, L., Jones, D., Corleto, R. et. al. (2019). The effect of synthetic and natural fire-retardants on burning and chemical characteristics of thermally modified teak (Tectona grandis L. f.) wood. Construction and Building Materials, 200, 551-558. doi: https://doi.org/10.1016/j.conbuildmat.2018.12.106

7. Zhao, P., Guo, C., Li, L. (2018). Flame retardancy and thermal degradation properties of polypropylene/wood flour composite modified with aluminum hypophosphite/melamine cyanurate. Journal of Thermal Analysis and Calorimetry, 135 (6), 3085-3093. doi: https://doi.org/10.1007/s10973-018-7544-9

8. Cirpici, B. K., Wang, Y. C., Rogers, B. (2016). Assessment of the thermal conductivity of intumescent coatings in fire. Fire Safety Journal, 81, 74-84. doi: https://doi.org/10.1016/j.firesaf.2016.01.011

9. Nine, M. J., Tran, D. N. H., Tung, T. T., Kabiri, S., Losic, D. (2017). Graphene-Borate as an Efficient Fire Retardant for Cellulosic Materials with Multiple and Synergetic Modes of Action. ACS Applied Materials \& Interfaces, 9 (11), 10160-10168. doi: https:// doi.org/10.1021/acsami.7b00572

10. Carosio, F., Alongi, J. (2016). Ultra-Fast Layer-by-Layer Approach for Depositing Flame Retardant Coatings on Flexible PU Foams within Seconds. ACS Applied Materials \& Interfaces, 8 (10), 6315-6319. doi: https://doi.org/10.1021/acsami.6b00598

11. Shi, X.-H., Chen, L., Zhao, Q., Long, J.-W., Li, Y.-M., Wang, Y.-Z. (2020). Epoxy resin composites reinforced and fire-retarded by surficially-treated carbon fibers via a tunable and facile process. Composites Science and Technology, 187, 107945. doi: https:// doi.org/10.1016/j.compscitech.2019.107945

12. Md Nasir, K., Ramli Sulong, N. H., Johan, M. R., Afifi, A. M. (2018). An investigation into waterborne intumescent coating with different fillers for steel application. Pigment \& Resin Technology, 47 (2), 142-153. doi: https://doi.org/10.1108/prt-09-2016-0089

13. Erdoğan, Y. (2016). Production of an insulation material from carpet and boron wastes. Bulletin of the Mineral Research and Exploration, 152, 197-202. doi: https://doi.org/10.19111/bmre.74700

14. Zhang, H., Li, Y.-M., Tao, W.-Q. (2017). Theoretical accuracy of anisotropic thermal conductivity determined by transient plane source method. International Journal of Heat and Mass Transfer, 108, 1634-1644. doi: https://doi.org/10.1016/ j.ijheatmasstransfer.2017.01.025

15. Potter, M. C. (2019). Engineering analysis. Springer. doi: https://doi.org/10.1007/978-3-319-91683-5

16. Tsapko, Y., Zavialov, D., Bondarenko, O., Marchenco, N., Mazurchuk, S., Horbachova, O. (2019). Determination of thermal and physical characteristics of dead pine wood thermal insulation products. Eastern-European Journal of Enterprise Technologies, 4 (10 (100)), 37-43. doi: https://doi.org/10.15587/1729-4061.2019.175346 